\title{
Combining Use of TRMM and Ground Observations of Annual Precipitations for Meteorological Drought Trends Monitoring in Morocco
}

\author{
Rachid Hadria ${ }^{1, \text { * }}$, Abdelghani Boudhar ${ }^{2,5}$, Hamza Ouatiki², Youssef Lebrini², \\ Loubna Elmansouri ${ }^{3}$, Fouad Gadouali ${ }^{4}$, Hayat Lionboui ${ }^{1}$, Tarik Benabdelouahab ${ }^{1}$ \\ ${ }^{1}$ Department of Environment and Natural Resources, National Institute of Agronomic Research, Rabat, Morocco \\ ${ }^{2}$ Faculty of Sciences and Technology, Sultan Moulay Slimane University, Beni Mellal, Morocco \\ ${ }^{3}$ Department of Topography, Hassan II Institute of Agronomy and Veterinary, Rabat, Morocco \\ ${ }^{4}$ East-central Regional Direction, National Meteorological Office, Beni Mellal, Morocco \\ ${ }^{5}$ Center for Remote Sensing Applications (CRSA), Mohammed VI Polytechnic University, Ben Guerir, Morocco
}

\section{Email address:}

r.hadria@gmail.com (R. Hadria), ab.boudhar@usms.ma (A. Boudhar), hamza.ouatiki@gmail.com (H. Ouatiki),

y.lebrini@gmail.com (Y. Lebrini), loubna.elmansouri@yahoo.fr (L. Elmansouri), gadoualif@gmail.com (F. Gadouali),

lionbouihayat@gmail.com (H. Lionboui), tarik.benabdelouahab@gmail.com (T. Benabdelouahab)

${ }^{*}$ Corresponding author

\section{To cite this article:}

Rachid Hadria, Abdelghani Boudhar, Hamza Ouatiki, Youssef Lebrini, Loubna Elmansouri, Fouad Gadouali, Hayat Lionboui, Tarik Benabdelouahab. Combining Use of TRMM and Ground Observations of Annual Precipitations for Meteorological Drought Trends Monitoring in Morocco. American Journal of Remote Sensing. Vol. 7, No. 2, 2019, pp. 25-34. doi: 10.11648/j.ajrs.20190702.11

Received: August 31, 2019; Accepted: September 25, 2019; Published: October 10, 2019

\begin{abstract}
The monitoring of drought statewide is a difficult issue especially when the national network of meteorological stations is sparse or do not cover the entire country. In this paper, rainfall satellite estimates derived from Tropical Rainfall Measuring Mission (TRMM) product have been used to evaluate the ability of remote sensing data to study the trends of annual precipitation in Morocco between 1998 and 2012. The standardized precipitation index, SPI, has been chosen to monitor meteorological drought in Morocco. Firstly, the accuracy of TRMM product to estimate annual rainfall was evaluated. Annual precipitations derived from 5113 daily TRMM data were compared to the corresponding rainfall measurements from 23 rain gauges. The results showed a general good linear relationship between TRMM and rain gauges data. When considering annual record, the Pearson correlation coefficient, $\mathrm{R}^{2}$, was equal to 0.73 and the root mean square error, RMSE, was equal to $159.8 \mathrm{~mm} /$ year. The correlation between rain gauge measurements and TRMM rainfall had been clearly improved when working with long-term annual average precipitation. The $\mathrm{R}^{2}$ increased to 0.79 and the RMSE decreased to $115,2 \mathrm{~mm}$. Secondly, the Mann-kendall tau coefficient, the Theil Sen slope and the contextual Mann-Kendall significance were used to analyze the SPI trends over Morocco. This analysis showed that mainly two regions appeared to be subject of significant trends during the studied period: The extreme north eastern of Morocco manifests a positive SPI trends and is more and more subject of extreme rainfall while the extreme south of the country is suffering from a decrease of annual precipitation which could represent significant socio-economic risks in these areas.
\end{abstract}

Keywords: Precipitation, Meteorological Drought, SPI, TRMM, Morocco

\section{Introduction}

Drought is a complex natural phenomenon that occurs under different climates conditions with important socioeconomic risks worldwide. According to the literature, this phenomenon is difficult to define and several definitions can be found. To our knowledge, the first scientific studies interested to the definition of drought started in the 1980s. Olukayode Oladipo (1985) and Wilhite and Glantz (1985) seem to be the first researchers to publish reviews on the definition and classification of drought [1-2]. In general, 
drought is associated with a prolonged period where precipitation is significantly below the normal value. This reduction can affect human, animals and natural resources. The determination of the normal value of rainfall in a given zone is a big issue in drought studies and defers between humid and dry environments. Another issue encountered when studying drought is the complexity to define when it starts and when it ends and thus, the effects of drought are observed after its occurrence [2].

Wilhite and Glantz (1985) published an interesting synthesis about the definition of drought [2]. They studied more than a hundred definitions of drought published in the literature and they have been grouped these definitions into four groups: meteorological, agricultural, hydrologic and socio-economic. All these definitions confirm that precipitation is the most important climate parameter affecting water availability and thus, has the largest contribution in drought phenomenon.

Indeed, rainfall is the main source of water for human, animal and crops around the world and is the main factor affecting the socio-economic development of billions of peoples, especially in developing countries and in arid and semi-arid zones where agriculture is the primary source of revenue [3]. This important meteorological variable is vital to fight against poverty and to contribute to social peace. In hydrological modelling, rainfall is a valuable information used generally as input to understand hydrological processes and quantify water balance components at watershed scale. For example, it is a key variable for rainfall-runoff modeling and aquifers recharge estimation. Rainfall is also extensively used in weather forecasting and to study climate changes on a global to local scale.

In Morocco, drought and floods are the major climate disasters. These events have required significant budgets to repair the resulting damage. They have revealed several weaknesses related to the vulnerability of the socio-economic fabric and basic infrastructure, as well as institutional, technical, and organizational shortcomings in the management of these events. Actually, Morocco has a multitude of legal texts that deal with issues related to the management of natural disasters. However, these texts had been proposed to meet specific needs and had not been made as part of a global vision that established a coherent strategy for the prevention and the control of natural disasters. This situation is mainly due, on the one hand, to the absence of a framework law on the prevention of risks and precisely identifying the competent authorities; and on the other hand, to the multiplicity of stakeholders that induces insufficient coordination and difficult to implement, or even conflicts of powers.

Considering the economic, environmental and social impacts of drought, scientists can study specific events and weather factors underlying to improve future preparedness of society. Therefore, drought study is usually based on drought indicators analysis, called also drought indices. These indicators are used to quantify drought and to identify its characteristics such as amplitude, duration, severity and spatial extent. Drought indices are also used to study the trends and the periodicity of drought from a long time series of precipitation data [4], and Mishra and Singh (2010) published an interesting review about the most known drought indices and their limitations [5].

The main challenge of studying drought is the lack of precipitation measurements over large geographic areas. The low spatial density of rain gauges, the accuracy of available measurements and the lack of rainfall archive at large spatial scale are the mains limiting problems. Such constraints are not specific to Morocco but concern almost every country in the world but in various importance levels. To overcome these problems, the use of remote sensing data appears to be the most efficient tool in terms of accuracy, spatial coverage as well as economical cost. In last twenty years, several precipitation data sets derived from various remote sensing products have been released. According to the approaches and algorithms applied to estimate precipitation amount, three sources of data can be considered: There are models that provide rainfall estimates using infrared satellite imagery, such as PERSIANN (Precipitation Estimation from Remote Sensing Information using Artificial Neural Network, [6]) and technics like CMORPH (CPC MORPHing technique, [7] that estimates rainfall based on passive microwave and infrared satellite data. There is finally TRMM (Tropical Rainfall Measurement Mission, a space mission that provides several products of rain estimates from a combination of passive microwave, visible/infrared and a rainfall radar data [8]. Among these sources of precipitation data at large geographic scale, TRMM, which was primarily designed to monitor and study tropical rainfall, have proved to be an important source of information in many application fields, such as monitoring global hydrological cycle [9-11], floods [12-14], and drought assessment [15-17] Indeed, the evaluation of TRMM data against rain gauges has been conducted in various previous studies around the world. Some studies have evaluated the rainfall estimates from TRMM in parallel with other satellite products [18-21]. Almazroui (2011) and Mantas et al. (2015) have focused their work on the TRMM product by evaluating its accuracy on different time steps and in different geographical and topographical contexts [22-23]. In addition to the direct comparison to rain gauges, Collischonn et al. (2008) provided an assessment based on hydrological modeling at a daily time step [24]. Islam and Uyeda (2007) compared daily rainfall from TRMM 3B42 to rain-gauge measurements over Bangladesh [25]. Huang et al. (2014) evaluated the TMPA V7 products with a relatively dense rain gauge network in Beijing and adjacent regions for an extreme precipitation event [26].

In Morocco, many research studies have been undertaken on using the TRMM products. Milewskiet al. (2015) have evaluated four TMPA 3B42 products (V6, V7 temporary, V7, reel time $\mathrm{V7}$ ) against rain gauges data depending on climatic zones and topography [27]. The study covered a large part of the Moroccan territory, but the analysis was conceived only about the average annual precipitation. The study conducted 
by Tramblay et al. (2016) over the Oued El Makhazine basin in northern Morocco shows the potential usefulness of these data in hydrological modeling [28]. Ouatiki et al. (2017) proved the accuracy of the TRMM 3B42 Version 7 product to estimate monthly and annual precipitation over the Oum Er Rbia Watershed in Morocco [29]. Recently, Gadouali and Messoulli (2018) compared four satellite derived rainfall products over Morocco at different seasons and topographic elevations and concluded that TRMM3B42V7 outperforms all the others, especially when using larger time steps [30].

Drought has occurred on average every three years over the last 30 years In Morocco. In this context and in order to enhance the national capacity to monitoring drought, with the aim of reducing the social, economic and environmental losses caused by drought, this paper analyzes the variability of this event's trends in Morocco between 1998 and 2012. The standardized precipitation index, SPI, has been chosen to analyze meteorological drought at the scale of the country. In the literature, this index is widely used to classify drought sequences [31-33]. This index, based only on precipitation data, has been recommended as a meteorological drought index by the World Meteorological Organization [34].

The specific objectives of the study are twofold:

1) Verifying the robustness and the accuracy of TRMM product to estimate annual rainfall at the scale of Morocco. To do so, we compared rainfall, derived from 5113 daily TRMM data to the corresponding gauge rainfall measurements between 1998 and 2012 from 23 rain gauges.

2) Studying the spatial variability of meteorological drought trends in Morocco based on SPI derived from TRMM data.

\section{Materials and Methods}

\subsection{Study Area}

The study area covers the whole country of Morocco (Figure 1) including its main agro-ecological zone. Morocco is characterized by strong climatological gradients from south to north and from west to east. Mean annual air temperatures vary between $12^{\circ} \mathrm{C}$ and $14^{\circ} \mathrm{C}$ in winter and $22^{\circ} \mathrm{C}$ and $24^{\circ} \mathrm{C}$ in summer, over the period $1950-2000$. The annual rainfalls vary from less than $150 \mathrm{~mm}$ in the southern desert to more than $1000 \mathrm{~mm}$ in northern Morocco [35]. According to Knippertz et al. (2003), the center and the north part of Morocco can be subdivided into three main regions, which are relatively homogeneous in term of rainfall: (1) the Atlantic region, including North and West of Morocco; (2) the Mediterranean region that includes the north-eastern part of the country and, (3) the Atlas mountains [36]. The climatic and topographic differences between these three regions strongly determine the types of agriculture crops and their yields in each zone.

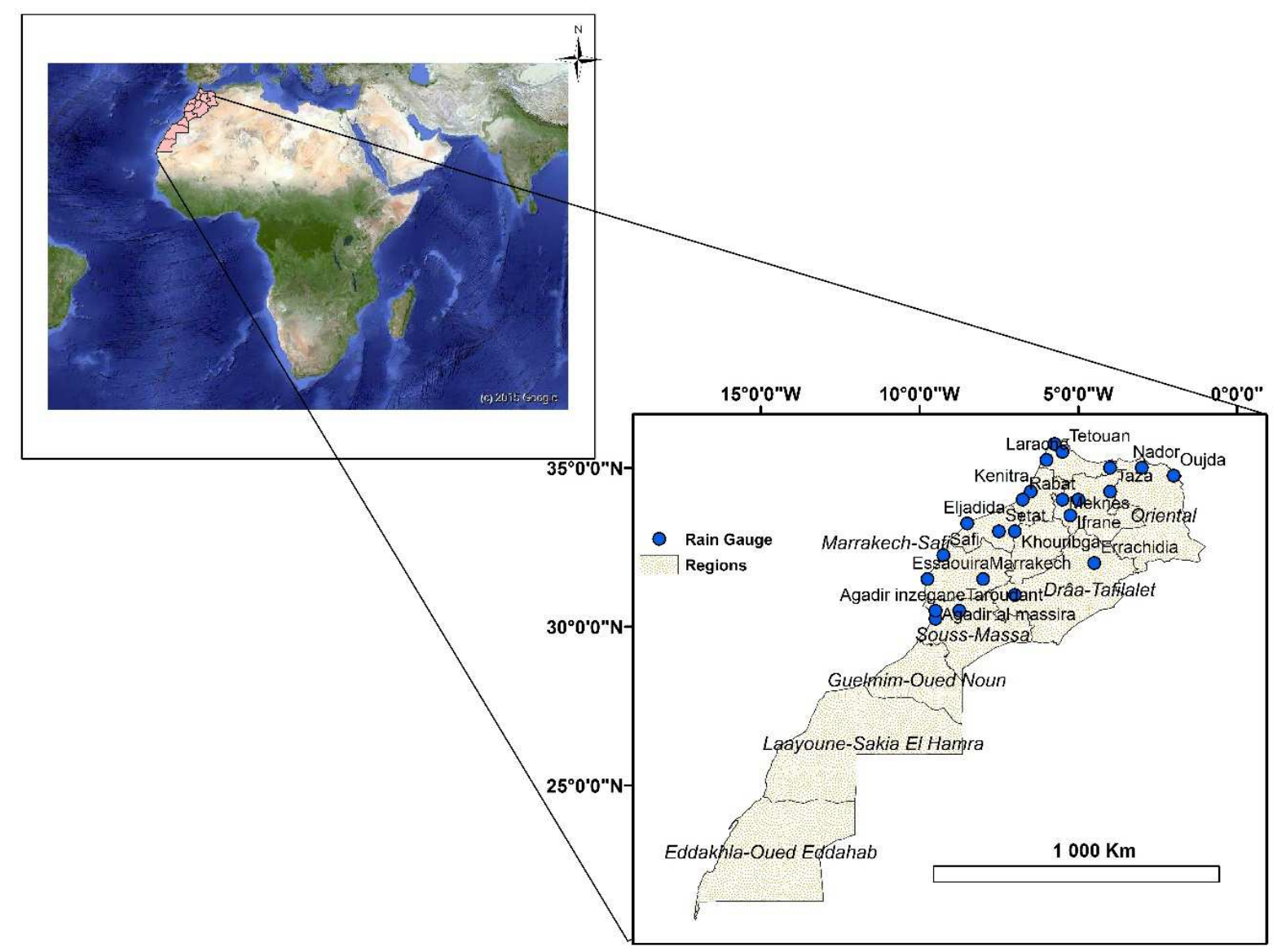

Figure 1. Delimitation of studied area showing the boundary of administrative regions. The blue disks show the distribution of used rain gauges. 


\subsection{Data}

Two data types are used in this study:

1. Daily rain data set were collected by 23 rain gauges distrubuted over the half north part of the study area (Figure 1) between 1998 and 2012. These data were acquired from the National Meteorological Office of Morocco, which is an official national administration. The rain gauge data used in this study were provided after undergoing quality control according to the recommendations of the World Meteorological Organization (WMO) and with less than $1 \%$ of missing data.

2. A time series of 5113 daily TRMM 3B42 Version 7 product, with a spatial resolution of $0.25^{\circ}$ (about 25 $\mathrm{km}$ ), were used. Tropical Measuring Mission is a joint mission of US National Aeronautics and Space Administration (NASA) and the Japan Aerospace Exploitation Agency (JAXA), designed to study tropical rainfall for weather and climate research. The main instruments used in precipitation are the TRMM Microwave Imager (TMI) and the precipitation Radar (PR) which contributes to form the TRMM Multisatellite Precipitation Analysis (TMPA) using Infrared brightness TMPA-derived products combined with global precipitation climatology center (GPCC), TMI and PR, produces the post-real-time TRMM3B42V7. This latter provides 3-hourly estimates with a spatial resolution of $0.25^{\circ}$ and a coverage from $50^{\circ} \mathrm{N}$ to $50^{\circ} \mathrm{S}$ [37]. The three hours estimates were aggregated to match the daily meteorological station measurement. These satellite-derived data used in this paper were acquired from NASA's official website of Tropical Rainfall Measuring Mission (https://pmm.nasa.gov/) for the period between 1 January 1998 and 31 August 2012.

The yearly time series of TRMM and ground gauged precipitation were prepared by summing up the daily values. In this paper, and due to the origin of each data type, we considered that rain gauges' measurements are more reliable than satellite precipitation estimates. Indeed, the accuracy of satellite precipitation estimates can be influenced by many factors related to surface and precipitations characteristics [38].

2.3. Methods 错误! 未找到引用源。Figure 2 illustrates the methodological approach proposed in this work. Firstly, annual precipitations were computed from daily rain gauges data and from daily TRMM data, respectively. Secondly, annual precipitations derived from TRMM data were compared to annual precipitations measured by the 23 rain gauges (Figure 1). The objective of this part was to verify the general accuracy of TRMM data to estimate annual precipitation at the scale of rain gauges, using the nearest point to pixel comparison method before extending the study to the whole country. We notice that point-to-pixel comparison approach can rises many methodological questions, especially in presence of important gradients of rainfall. However, this method is widely used in the literature and remains one of the mains methods to evaluate satellitederived rainfall [39-40].

Then, the standardized precipitation index, SPI, had been calculated from both gauges measurements set and TRMM data for the 23 rain gauges. The equation used to compute this drought index is given by the following formula (1).

$$
S P I=\frac{(P i-P m)}{S}
$$

where $p_{i}$ is the annual rainfall of the year $i ; P_{m}$ is the average rainfall during the whole studied period and $S$ is the standard deviation of rainfall during the whole studied period. SPI drought index values computed from rain gauges data set were compared to those computed from TRMM data.

Drougt trends have been looked for and captured at the scale of the country based on the non-parametric MannKendall trend test [41-42]. Such method have been widelly used in the litteraure to assess monotonic trend in environmental time series data [43-44]. It is a particular case of the Kendall Tau coefficient, that quantifies the dependency between two variables, where the serie is the dependent variable and time is the independenet one. The main objective of the Mann-Kendall test is to evaluate the existence of trend and state whether the data increases or decreases over time.

At different stages of this work, two statistical indices were calculated to analyze the relationships between indicators computed from gauges data set and those derived from TRMM data. These indices were the Pearson correlation coefficient $\left(\mathrm{R}^{2}\right)$ and the root mean square error (RMSE).

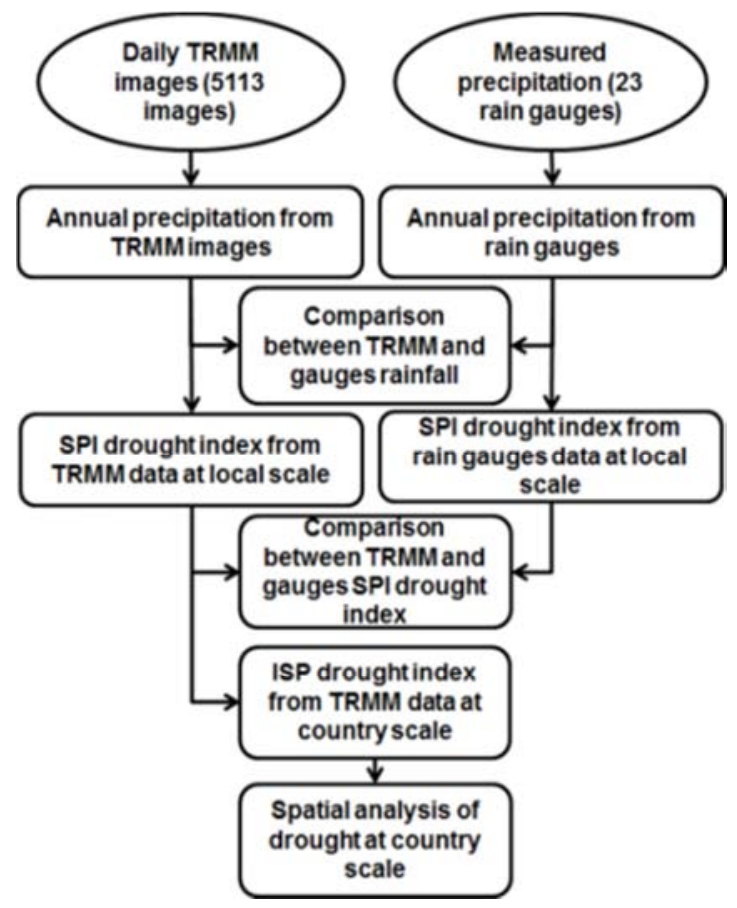

Figure 2. Flowchart of proposed methodology and a synthesis of used data. 


\section{Results and Discussions}

\subsection{Overall Assessment of TRMM Product at Annual Time Step}

The scatterplot presented in Figure 3 compares annual precipitations measured by the 23 rain gauges and those derived from TRMM between 1998 and 2012. Presented data gives a first general idea about the variability of annual rainfall in Morocco. Annual rainfall varies generally between less than $100 \mathrm{~mm}$ and $1000 \mathrm{~mm}$ with some extremes values that can reach $1600 \mathrm{~mm}$. The comparison shows also a general good linear relationship between the TRMM and rain gauges data. When considering all rain gauges together, the Pearson correlation coefficient, $\mathrm{R}^{2}$, is equal to 0.73 and the root mean square error, RMSE, is equal to $159.8 \mathrm{~mm}$. When analyzing the rain gauges separately, the $\mathrm{R}^{2}$ varies between 0.43 and 0.92 with nearly $74 \%$ of the rain gauges having $R^{2}$ higher than 0.60 , and the RMSE varies between $38 \mathrm{~mm}$ and $318 \mathrm{~mm}$ with more than $82 \%$ of the rain gauges having RMSE lower than $200 \mathrm{~mm}$. These results are consistent with the previous studies and confirm the good performance of TRMM data at the annual time scale [27, 29].

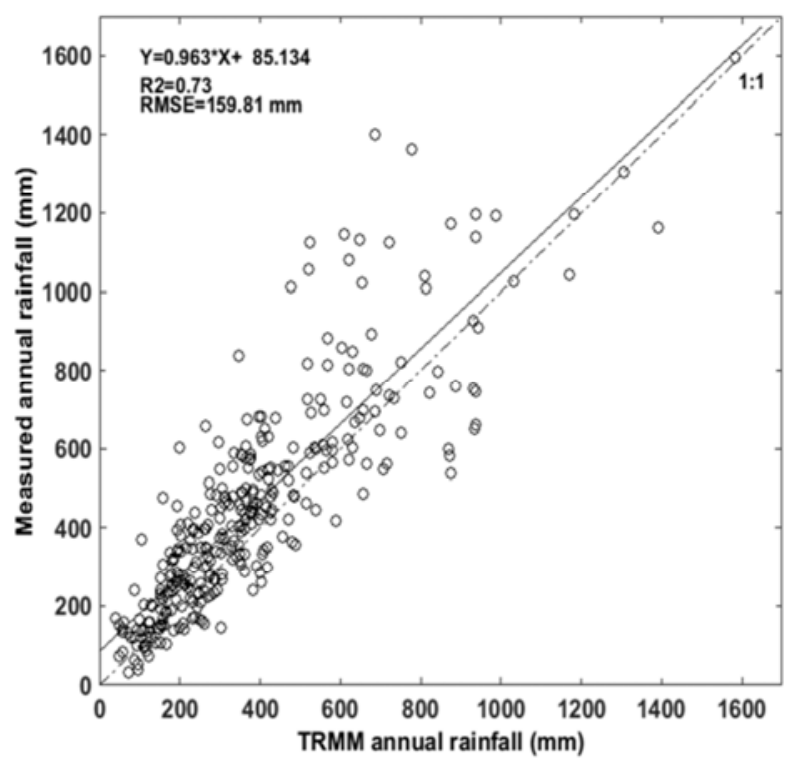

Figure 3. Comparison between annual precipitations derived from TRMM data and rain gauges measurements in Morocco between 1998 and 2012.

Figure 4 illustrates the relationship between annual average precipitations measured by the 23 rain gauges and those retrieved from TRMM data between 1998 and 2012. The overall distribution of the annual averages of precipitation derived from TRMM is in a good agreement with the normal annual measured by the majority of rain gauges. This figure also shows a high correlation between insitu measurements and TRMM average annual precipitations with $\mathrm{R}^{2}$ equal to 0.79 and RMSE equal to $115.2 \mathrm{~mm}$. Both Figure 3 and Figure 4 showed that in-situ gauges precipitation is generally superior to TRMM precipitation. Such remark has been already observed in previous studies in the literature in Morocco [28-29, 33], in Bangladesh [25] and in Saudi Arabia [22]. Regarding seasonality and temporal impact on satellite products accuracy, TRMM product produces the observed annual cycle with an overestimation or underestimation of rainfall amount during rainy seasons and dry seasons, respectively [45]. In the Moroccan context of hydro-climatic heterogeneities, the agreement between TRMM and ground data is more significant in the plain area (arid/semi-arid) than the mountainous zones with an overall acceptable accuracy [27, 29].

The comparison presented in this section showed that the correlation between gauge precipitations and TRMM rainfall had been clearly improved when working with long-term annual average precipitation. Indeed, the coefficient of correlation $\mathrm{R}^{2}$ increased from 0.73 to 0.79 and the RMSE decreased from $159,8 \mathrm{~mm}$ to $115,2 \mathrm{~mm}$. Such result is very important in the context of this study since we are interested to analyzing to drought trends at the scale of Morocco using TRMM data. Despite the lack of rain gauges in the south part of studied area, the existing gauge network used in this study cover the main climate classes of Morocco (arid, semi-arid, sub-humid and humid). Indeed, figure 3 showed that the minimum measured annual rainfall was $49 \mathrm{~mm} /$ year. In addition, agricultural areas are concentrated in the center and in the north parts of the country. For these reasons, we choose to monitor drought based on TRMM datasets over the whole Moroccan territory despite the absence of gauges in the south.

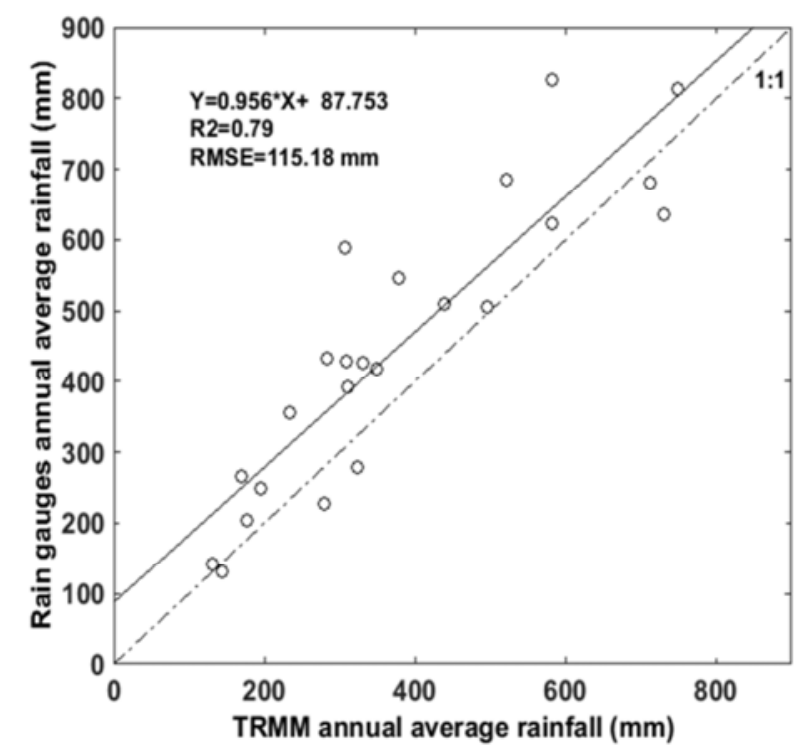

Figure 4. Comparison between annual average precipitations measured by the 23 rain gauges and those retrieved from TRMM data between 1998 and 2012 .

\subsection{Comparison Between Drought Indices from Rain Gauges Data and TRMM Precipitations at Rain Gauges Scale}

Figure 5 compares the values of the SPI drought indices derived from TRMM data and those calculated from the 23 rain gauges measurements between 1998 and 2012. The scatterplot shows a good relationship between the values of 
SPI computed from the two different sources of precipitation data, with $\mathrm{R}^{2}$ and RMSE equal to 0.64 and 0.66 , respectively.

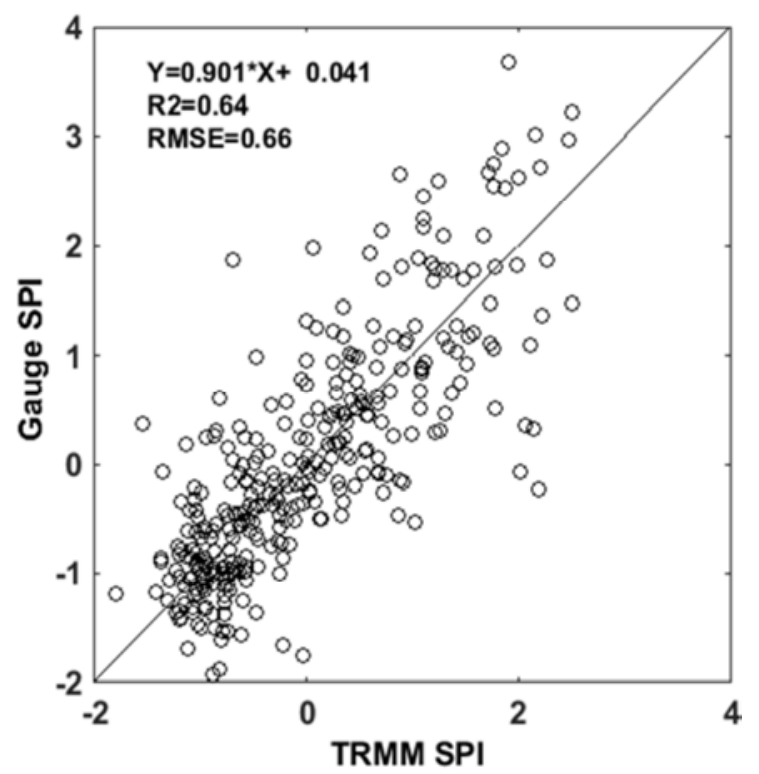

Figure 5. Comparison between SPI drought indices derived from TRMM data and those calculated from the 23 rain gauges measurements between 1998 and 2012

The analysis of rain gauges separately shows that the $\mathrm{R}^{2}$ varies between 0.43 and 0.93 with nearly $70 \%$ of the 23 considered rain gauges have $\mathrm{R}^{2}$ higher than 0.60 . These results prove the good correlation between the SPI drought index computed from in-situ measurements and that retrieved from TRMM precipitation in different locations of Morocco. It is thus justified to use SPI drought index retrieved from TRMM data to analyze drought and precipitation anomalies at the scale of the country. Figure 5 shows also that the values of SPI index cover many drought categories as classified by McKee et al. (1993) and by Hayes et al., (1999) starting from severe drought $(-1.99<\mathrm{SPI}<-1.5)$ to very wet $(0.5<\mathrm{SPI}<2) \quad[31,46]$. This classification is in good concordance with those observed in Morocco by Ezzine et al. (2014) [33].

Figure 6 presents the variation of SPI drought indices from rain gauges data and TRMM precipitations at rain gauges points between 1998/1999 and 2011/2012. The inter-annual variation of cumulated rainfall between September and May at the country level, extracted from [35], are also presented to help interpreting the inter-annual variation of SPI values. Firstly, these results showed that both in-situ measurements and TRMM precipitations present an alternation between positive and negative values of SPI drought index from one year to another. This alternation reproduces in reality the succession of dry and humid years in Morocco. For example, the years 1998/1999, 1999/2000, 2000/2001, 2004/2005, $2006 / 2007,2007 / 2008$ and 20011/2012 are considered as dry years while the years 2002/2003, 2003/2004, 2005/2006, 2008/2009, 2009/2010 and 2010/2011 are classified as normal to wet. Indeed, the annual cumulated rainfalls of the first group of dry years are under the average value of precipitation presented by the dotted line in the subplot three of Figure 6, while the annual cumulated rainfalls of the second group of wet years are over the average value of precipitation. This phenomenon is a very known characteristic of Moroccan climate and that affects directly the final agricultural production since Moroccan agriculture is directly dependent on annual precipitation in terms of both temporal distribution and annual cumulus $[33,35]$.

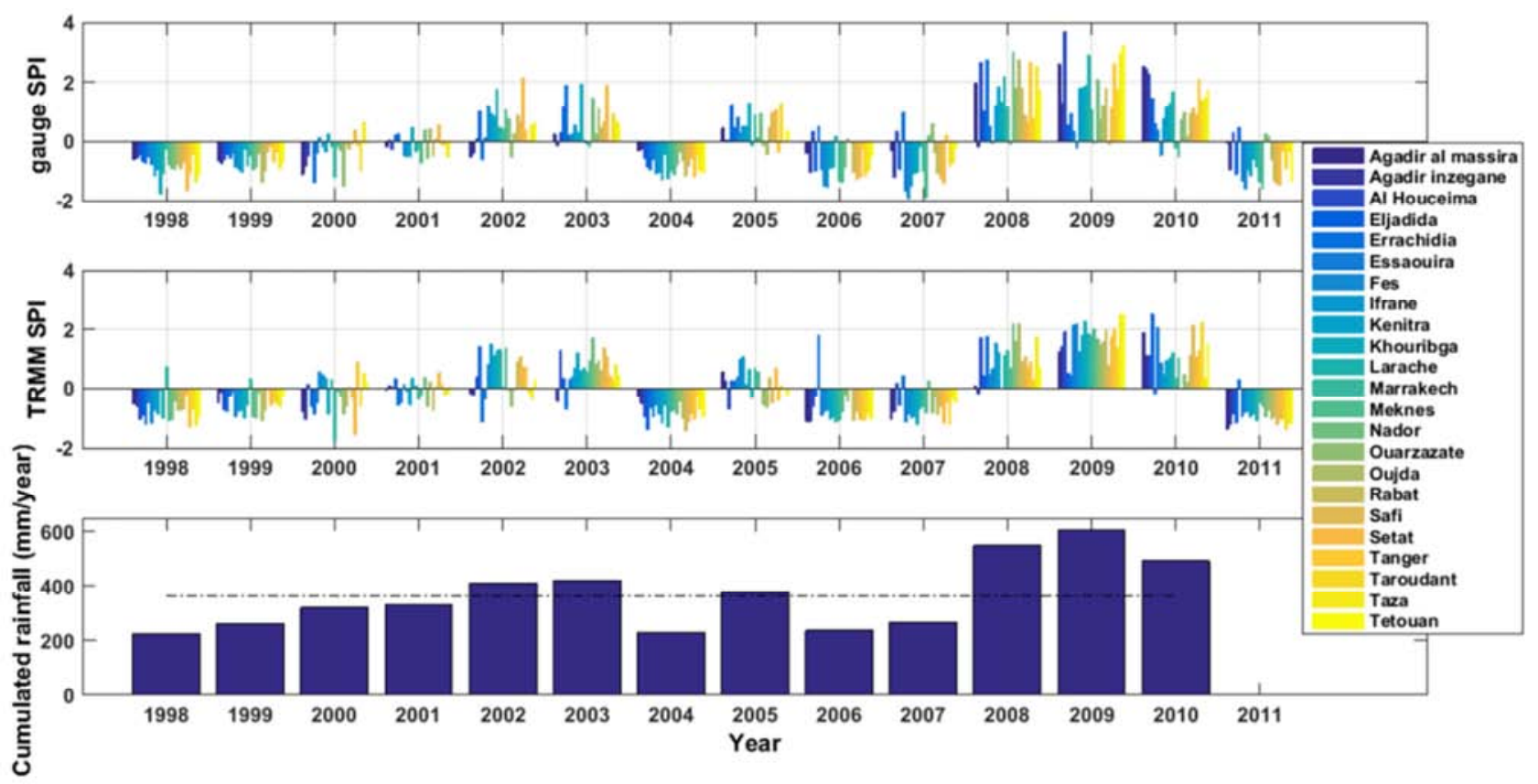

Figure 6. Variation of SPI drought indices from rain gauges and TRMM precipitations at rain gauges location scale between 1998 and 2012 and the interannual variation of cumulated rainfall between September and May, at the country level, for 1998 to2012. Dotted line in the last subplot shows the average value of annual precipitation. 


\subsection{Spatial Analysis of Drought Trends over Morocco}

In this section, the spatial trends of drought over Morocco will be performed through analyzing the trends' variably of the SPI drought index. To do that, three estimators were chosen: the monotonic trend (Mann-Kendall), the Kendall Slope (Theil-Sen) and the Mann-Kendall significance.

The monotonic trend analysis of the SPI drought index was performed to measure the degree to which drought occurrence is consistently increasing or decreasing during the studied period. The spatial variability of this estimator is displayed in Figure 7 where positive values of Mann-Kendall tau indicate an increasing trend and negative values indicate a decreasing trend in the time series. Globally, this test showed a mixture of positive and negative trends over different regions of Morocco. The south territory part of the country, located in the Eddakhla-Oued Eddahab and Layoune-Sakia El Hamra regions, exhibited downward trends of the SPI index (red pixels in Figure 7). However, the rest of the country, especially the center and the eastern regions (Drâa-Tafilalet and Oriental region), the MannKendall tau is marked by an upward trends.

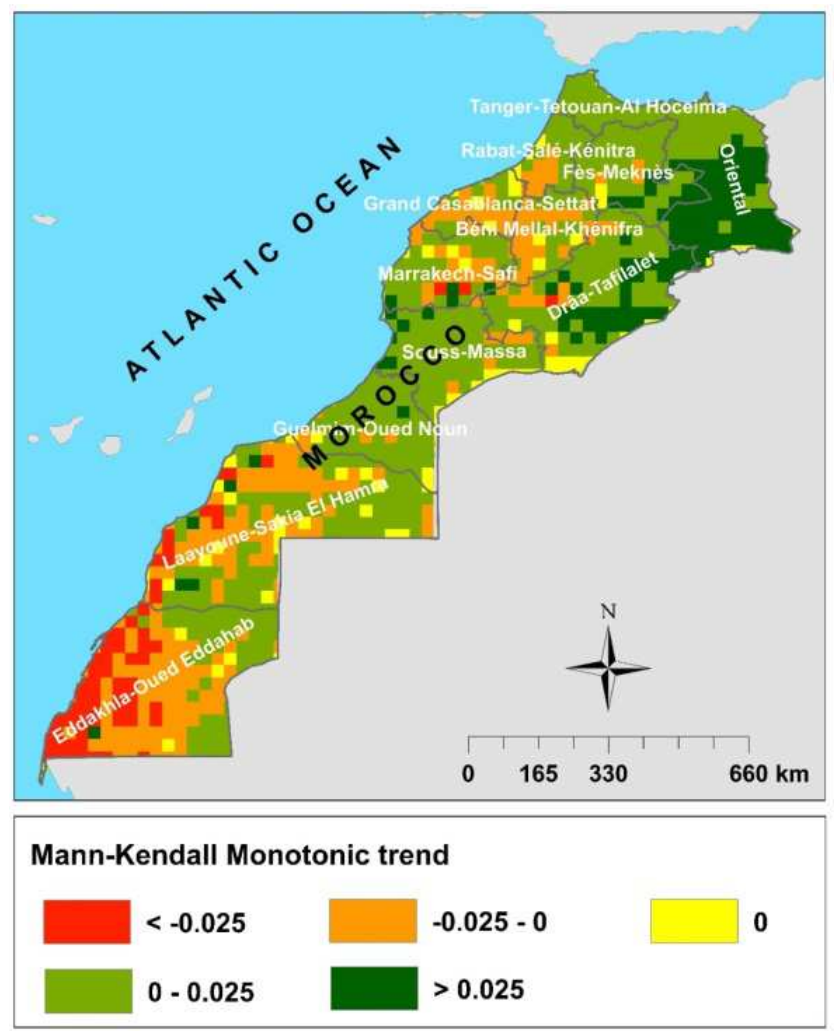

Figure 7. Spatial variability of the monotonic trend of the SPI drought index over Morocco. The solid line shows the official borders of the 12 administrative regions of the country.

In order to highlight the magnitude of observed trends illustrated by Figure 7, the Theil-Sen slope has been computed according to Sen's method. The spatial variability of Sen's slope is presented in Figure 8. Positive slope means an increase of SPI while negative slope means a decrease of
SPI. Figure 8 shows that positive values of Theil Sen slope are observed mainly in the regions of Guelmim-Oued Noun, Souss-Massa, Drâa-Tafilalet, Fes-Meknès, Tanger-Tetouan$\mathrm{Al}$ Houceima and Oriental. The highest positive slope values were observed in the extreme eastern boundary of Morocco (south of Drâa-Tafilalet and Oriental regions). These regions, largely dominated by rangeland area (about four million hectares), receive less than $100 \mathrm{~mm}$ of precipitation per year and are subject to strong desertification phenomena. Observed positive trend of SPI may be explained by an increase in rainfall amounts due to the extreme rainfall events that causes damages affecting the vegetation cover and accelerates soil degradation. To verify this hypothesis, we examine the evolution of daily extreme rainfall over these regions from 1998 to 2012 by calculating the number of occurrences of days with total rainfall (estimated by TRMM) above the 0.99 quantile (Q99). To do this, pixels belonging to the aforementioned regions were randomly selected. Figure 9 shows an evident increase of the number of days with extreme rainfall which supports the hypothesis of that the observed positive trend is mainly related to the increase of daily extreme rainfall events.

Negative values of the Theil-Sen slope are mainly observed in the extreme south of Morocco (South of DakhlaOued Eddahab and Laayoune-Sakia El Hamra regions). This desert region is characterized by arid climate and very low annual precipitation (less than $50 \mathrm{~mm} / \mathrm{year}$ ). The negative trend of SPI could be explained by a decrease in rainfall amounts due to global climate change in the south of Morocco.

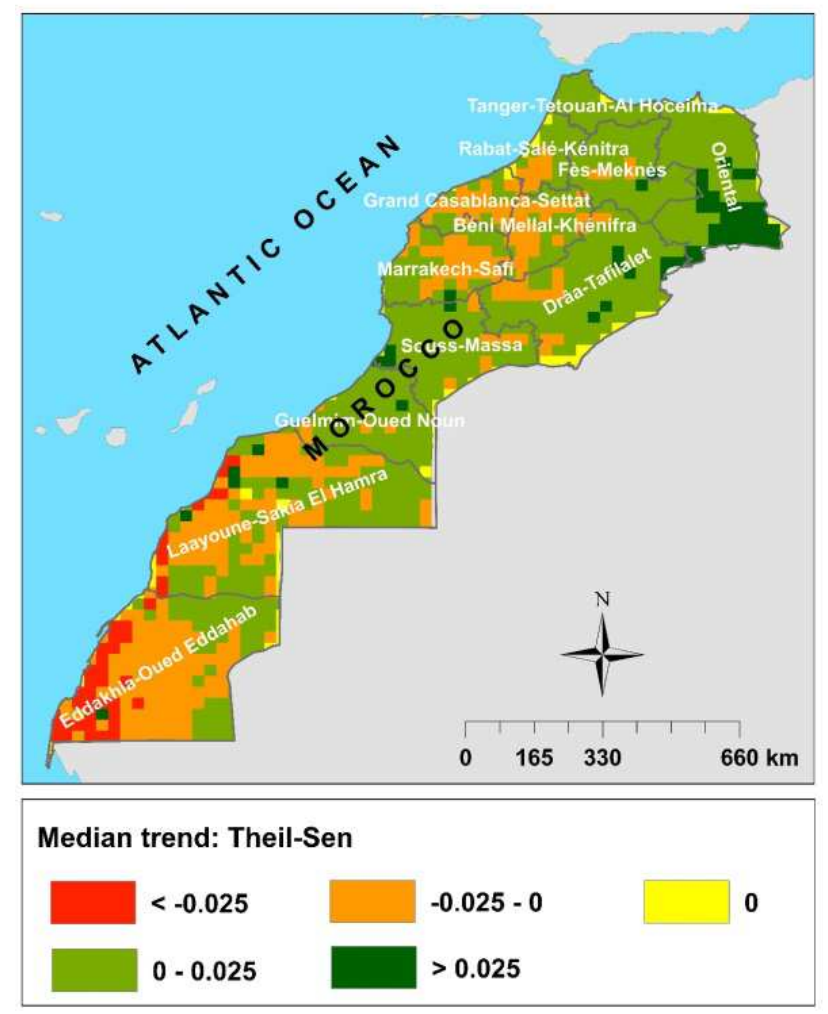

Figure 8. Spatial variability of the Theil Sen slope trends over Morocco 


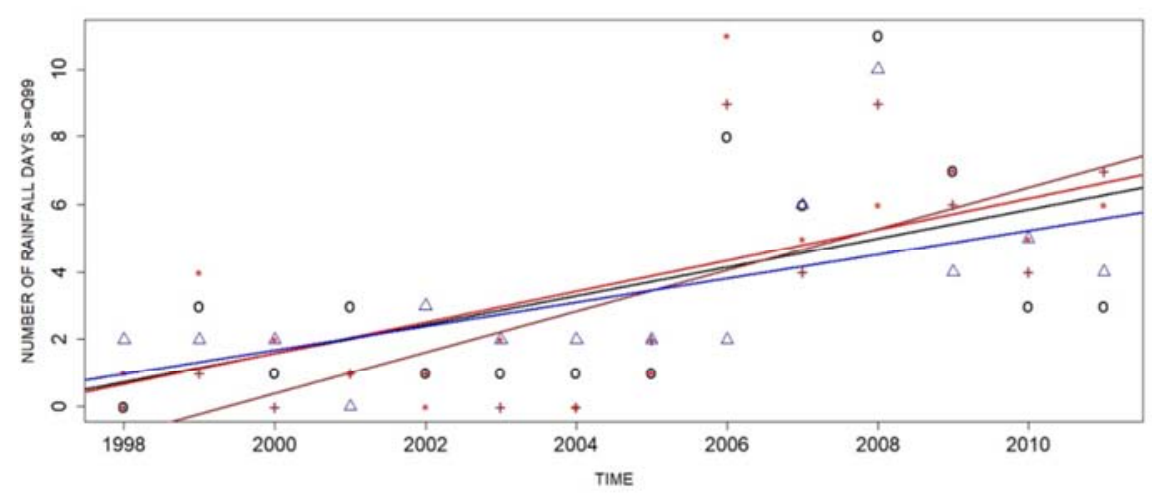

Figure 9. Evolution of daily rainfall above the 0.99 quantile for pixels from Daraa Tafilalet and Oriental regions.

Finally, to quantify the significance of observed trends of SPI drought index, Figure 10 shows the spatial variability of the contextual Mann-Kendall significance (the $p$-value) of SPI trends over Morocco. This result confirmed the previous ones and showed that aforementioned trends of SPI drought index are statistically significant mainly in the western part of the Eddakhla-Oued Eddahab and Laayoune-Sakia El Hamra regions (south) and in the south of Drâa-Tafilatet and Oriental regions (east). For the southern (desert) part of the country, obtained results indicate a significant increase of drought events using SPI index from TRMM data. Similar finding was found by Filahi et al. (2016) using precipitations records at local stations and showed a tendency towards drier conditions in the south of morocco [47]. Contrariwise, a decrease of drought phenomena was observed in eastern regions. As it was aforementioned, this last part of the country is subject of local extreme rainfall events contributing to significant increase in total annual precipitations.

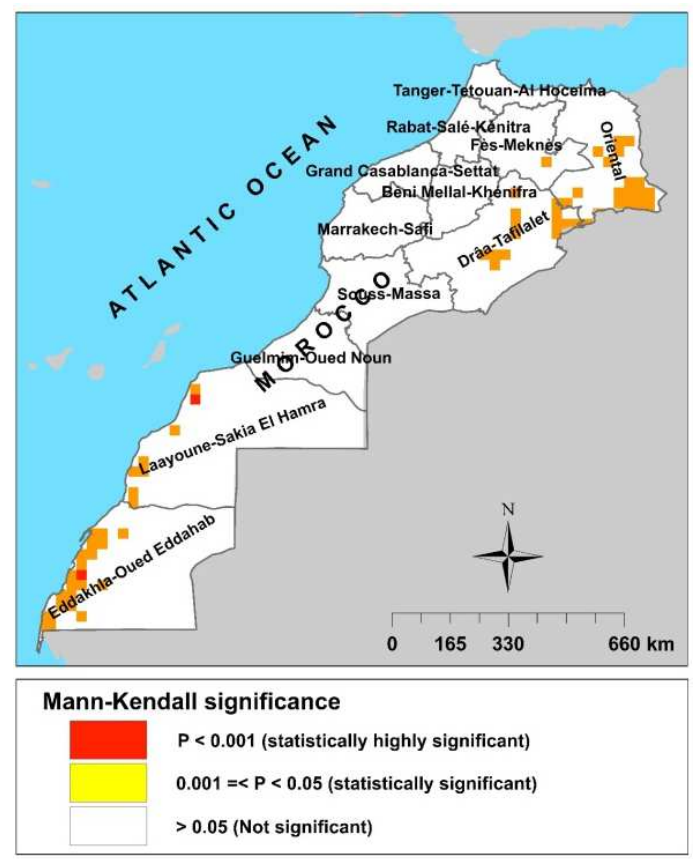

Figure 10. Spatial variability of the contextual Mann-Kendall significance over Morocco.

\section{Conclusions, Recommendations and Perspectives}

Morocco's economy is vulnerable to drought, which is the main obstacle to the expansion of the agricultural sector. Thereby, this paper focused on the evaluation of the potential of TRMM derived rainfall to monitor meteorological drought trends over agricultural areas of Morocco during a short period between 1998 and 2012. To do that, the standardized precipitation index was used to analyze meteorological droughts and to study the variability of drought trends in Morocco during the studied period.

Firstly, the robustness and the accuracy of TRMM product to estimate annual rainfall in Morocco were evaluated. Annual precipitations derived from 5113 daily TRMM data were compared with the corresponding gauge rainfall measurements, between 1998 and 2012, from 23 rain gauges. The results showed a good relationship between the values computed from the two different sources of precipitation data. When considering annual data, the Pearson correlation coefficient, $\mathrm{R}^{2}$, was equal to 0.73 and the root mean square error, RMSE, was equal to $159.8 \mathrm{~mm} /$ year. The correlation between gauge measurements and TRMM rainfall had been clearly improved when working with long term annual average precipitation. Indeed, the $\mathrm{R}^{2}$ increased from 0.73 to 0.79 and the RMSE decreased from $159,8 \mathrm{~mm}$ to $115,2 \mathrm{~mm}$.

Secondly, Mann-Kendall tests were used to study the trends of drought variability over Morocco between 1998 and 2012. The Mann-Kendall tau coefficient, the Theil Sen slope and the contextual Mann-Kendall significance were used to analyze SPI trends over Morocco. This analysis showed that mainly two regions appeared to be subject of significant trends during the period between 1998 and 2012: The extreme north eastern of Morocco exhibited an increase in annual precipitations accompanied with the increase of daily extreme rainfalls, while a decrease trend is observed over the extreme south of the country. Indeed, positive values of Theil Sen slope were observed mainly in the regions of GuelmimOued Noun, Souss-Massa, Drâa-Tafilalet, Fes-Meknès, Tanger-Tetouan-Al Houceima and Oriental. The highest positive slope values were observed in the extreme eastern boundary of Morocco (south of Drâa-Tafilalet and Oriental 
regions). These regions, largely dominated by rangeland area (about four million hectares), receive less than $100 \mathrm{~mm}$ of precipitation per year and are subject to strong desertification phenomena. Observed positive trend of SPI may be explained by an increase in rainfall amounts due to the extreme rainfall events, mainly in summer, that causes damages affecting the vegetation cover and accelerates soil degradation. Further analysis based on longer precipitation time series is needed to confirm or infirm such finding.

Despite of the short period covered by this work, the results obtained showed the ability of remote sensing data (TRMM data in this case study) to monitor drought over large spatial scale trough the simple standardized precipitation index, SPI. Such data could be a good tool to study drought especially in zones where metrological stations are not available. However, these findings need to be improved by testing new data and working on longer periods. Also, the extreme phenomena are difficult to avoid, but their effects could be mitigated if we have knowledge on the history of meteorological events tendency of each area. Finally, it could be more interesting to extend this study to the whole part including North of Africa and south of Europe to better understand the drought trend in these regions.

\section{Acknowledgements}

Historical precipitation data used in this study is provided by the National Meteorological office of Morocco in the framework of E-AGRI project (http://www.e-agri.info/). The authors thank all the persons making this data available for us.

\section{References}

[1] Olukayode Oladipo, E. (1985). A comparative performance analysis of three meteorological drought indices. Journal of Climatology 5, 655-664.

[2] Wilhite, D. A. and M. H. Glantz (1985). Understanding: the Drought Phenomenon: The Role of Definitions. Water International 10, 111-120.

[3] Schilling, J., K. P. Freier, E. Hertig, and J. Scheffran (2012). Climate change, vulnerability and adaptation in North Africa with focus on Morocco. Agriculture, Ecosystems \& Environment 156, 12-26.

[4] Merino, A., L. López, L. Hermida, J. L. Sánchez, E. GarcíaOrtega, E. Gascón, and S. Fernández-González (2015). Identification of drought phases in a 110-year record from Western Mediterranean basin: Trends, anomalies and periodicity analysis for Iberian Peninsula. Global and Planetary Change 133, 96-108.

[5] Mishra, A. K. and V. P. Singh (2010). A review of drought concepts. Journal of Hydrology 391, 202-216.

[6] Hsu, K.-1., X. Gao, S. Sorooshian, and H. V. Gupta (1997). Precipitation Estimation from Remotely Sensed Information Using Artificial Neural Networks. Journal of Applied Meteorology 36, 1176-1190.

[7] Joyce, R. J., J. E. Janowiak, P. A. Arkin, and P. Xie (2004).
CMORPH: A Method that Produces Global Precipitation Estimates from Passive Microwave and Infrared Data at High Spatial and Temporal Resolution. Journal of Hydrometeorology 5, 487-503.

[8] Kummerow, C., W. Barnes, T. Kozu, J. Shiue, and J. Simpson (1998). The Tropical Rainfall Measuring Mission (TRMM) Sensor Package. Journal of Atmospheric and Oceanic Technology 15, 809-817.

[9] Su, F., Y. Hong, and D. P. Lettenmaier (2008). Evaluation of TRMM Multisatellite Precipitation Analysis (TMPA) and Its Utility in Hydrologic Prediction in the La Plata Basin. Journal of Hydrometeorology 9, 622-640.

[10] Gu, H.-h., Z.-b. Yu, C.-g. Yang, Q. Ju, B.-h. Lu, and C. Liang (2010). Hydrological assessment of TRMM rainfall data over Yangtze River Basin. Water Science and Engineering 3, 418430 .

[11] Arvor D., Dubreuil V., Ronchail J., and P. S. (2008). Apport des données TRMM 3B42 à l'étude des précipitations au Mato Grosso. Climatologie 5, 49-69.

[12] Di Paola, F., E. Ricciardelli, D. Cimini, F. Romano, M. Viggiano, and V. Cuomo (2014). Analysis of Catania Flash Flood Case Study by Using Combined Microwave and Infrared Technique. Journal of Hydrometeorology 15, 19891998.

[13] Li, L., Y. Hong, J. Wang, R. F. Adler, F. S. Policelli, S. Habib, D. Irwn, T. Korme, and L. Okello (2009). Evaluation of the real-time TRMM-based multi-satellite precipitation analysis for an operational flood prediction system in Nzoia Basin, Lake Victoria, Africa. Natural Hazards 50, 109-123.

[14] Moffitt, C. B., F. Hossain, R. F. Adler, K. K. Yilmaz, and H. F. Pierce (2011). Validation of a TRMM-based global Flood Detection System in Bangladesh. International Journal of Applied Earth Observation and Geoinformation 13, 165-177.

[15] Zhang, A. and G. Jia (2013). Monitoring meteorological drought in semiarid regions using multi-sensor microwave remote sensing data. Remote Sensing of Environment 134, 12-23.

[16] Du, L., Q. Tian, T. Yu, Q. Meng, T. Jancso, P. Udvardy, and Y. Huang (2013). A comprehensive drought monitoring method integrating MODIS and TRMM data. International Journal of Applied Earth Observation and Geoinformation 23, 245-253.

[17] Yaduvanshi, A., P. K. Srivastava, and A. C. Pandey (2015). Integrating TRMM and MODIS satellite with socio-economic vulnerability for monitoring drought risk over a tropical region of India. Physics and Chemistry of the Earth, Parts $\mathrm{A} / \mathrm{B} / \mathrm{C} 83,14-27$.

[18] Brown, J. E. M. (2006). An analysis of the performance of hybrid infrared and microwave satellite precipitation algorithms over India and adjacent regions. Remote Sensing of Environment 101, 63-81.

[19] Dinku, T., S. Chidzambwa, P. Ceccato, S. J. Connor, and C. F. Ropelewski (2008). Validation of high-resolution satellite rainfall products over complex terrain. International Journal of Remote Sensing 29, 4097-4110.

[20] Baik, J. and M. Choi (2015). Spatio-temporal variability of remotely sensed precipitation data from COMS and TRMM: Case study of Korean peninsula in East Asia. Advances in Space Research 56, 1125-1138. 
[21] Blacutt, L. A., D. L. Herdies, L. G. G. de Gonçalves, D. A. Vila, and M. Andrade (2015). Precipitation comparison for the CFSR, MERRA, TRMM3B42 and Combined Scheme datasets in Bolivia. Atmospheric Research 163, 117-131.

[22] Almazroui, M. (2011). Calibration of TRMM rainfall climatology over Saudi Arabia during 1998-2009. Atmospheric Research 99, 400-414.

[23] Mantas, V. M., Z. Liu, C. Caro, and A. J. S. C. Pereira (2015). Validation of TRMM multi-satellite precipitation analysis (TMPA) products in the Peruvian Andes. Atmospheric Research 163, 132-145.

[24] Collischonn, B., W. Collischonn, and C. E. M. Tucci (2008). Daily hydrological modeling in the Amazon basin using TRMM rainfall estimates. Journal of Hydrology 360, 207-216.

[25] Islam, M. N. and H. Uyeda (2007). Use of TRMM in determining the climatic characteristics of rainfall over Bangladesh. Remote Sensing of Environment 108, 264276 .

[26] Huang, Y., S. Chen, Q. Cao, Y. Hong, B. Wu, M. Huang, L. Qiao, Z. Zhang, Z. Li, W. Li, and X. Yang (2014). Evaluation of Version-7 TRMM Multi-Satellite Precipitation Analysis Product during the Beijing Extreme Heavy Rainfall Event of 21 July 2012. Water 6, 32 .

[27] Milewski, A., R. Elkadiri, and M. Durham (2015). Assessment and Comparison of TMPA Satellite Precipitation Products in Varying Climatic and Topographic Regimes in Morocco. Remote Sensing 7, 5697.

[28] Tramblay, Y., V. Thiemig, A. Dezetter, and L. Hanich (2016). Evaluation of satellite-based rainfall products for hydrological modelling in Morocco. Hydrological Sciences Journal 61, 2509-2519.

[29] Ouatiki, H., A. Boudhar, Y. Tramblay, L. Jarlan, T. Benabdelouhab, L. Hanich, M. El Meslouhi, and A. Chehbouni (2017). Evaluation of TRMM 3B42 V7 Rainfall Product over the Oum Er Rbia Watershed in Morocco. Climate 5,1 .

[30] Gadouali, F. and M. Messoulli (2018). Evaluation of multiple satellite-derived rainfall products over Morocco. International Journal of Hydrology Science and Technology. (in press).

[31] McKee, T. B. (1993). The Relationship of Drought Frequency and Duration of Time Scales. Eighth Conference on Applied Climatology, January, Anaheim, California, 1993 17-22.

[32] Fjelde, H. and N. von Uexkull (2012). Climate triggers: Rainfall anomalies, vulnerability and communal conflict in Sub-Saharan Africa. Political Geography 31, 444-453.

[33] Ezzine, H., A. Bouziane, and D. Ouazar (2014). Seasonal comparisons of meteorological and agricultural drought indices in Morocco using open short time-series data. International Journal of Applied Earth Observation and Geoinformation 26, 36-48.

[34] Hayes, M., M. Svoboda, N. Wall, and M. Widhalm (2011). The Lincoln Declaration on Drought Indices: Universal Meteorological Drought Index Recommended. Bulletin of the American Meteorological Society 92, 485-488.
[35] Balaghi, R., M. Jlibene, B. Tychon, and H. Eerens, Agrometeorological cereal yield forecasting in Morocco. 2013 ed. 2013, National Institute of Agronomic Research (INRA): Devision of information and communication (INRA). 157.

[36] Knippertz, P., M. Christoph, and P. Speth (2003). Long-term precipitation variability in Morocco and the link to the largescale circulation in recent and future climates. Meteorology and Atmospheric Physics 83, 67-88.

[37] Huffman, G. J., D. T. Bolvin, E. J. Nelkin, D. B. Wolff, R. F. Adler, G. Gu, Y. Hong, K. P. Bowman, and E. F. Stocker (2007). The TRMM Multisatellite Precipitation Analysis (TMPA): Quasi-Global, Multiyear, Combined-Sensor Precipitation Estimates at Fine Scales. Journal of Hydrometeorology 8, 38-55.

[38] Carr, N., P.-E. Kirstetter, Y. Hong, J. J. Gourley, M. Schwaller, W. Petersen, N.-Y. Wang, R. R. Ferraro, and X. Xue (2015). The Influence of Surface and Precipitation Characteristics on TRMM Microwave Imager Rainfall Retrieval Uncertainty. Journal of Hydrometeorology 16, 1596-1614.

[39] Wang, J. and D. B. Wolff (2010). Evaluation of TRMM Ground-Validation Radar-Rain Errors Using Rain Gauge Measurements. Journal of Applied Meteorology and Climatology 49, 310-324.

[40] Cohen Liechti, T., J. P. Matos, J. L. Boillat, and A. J. Schleiss (2012). Comparison and evaluation of satellite derived precipitation products for hydrological modeling of the Zambezi River Basin. Hydrol. Earth Syst. Sci. 16, 489-500.

[41] Kendall, M. G. (1938). A New Measure of Rank Correlation. Biometrika 30, 81-93.

[42] Mann, H. B. (1945). Nonparametric Tests Against Trend. Econometrica 13, 245-259.

[43] McLeod, A. I., K. W. Hipel, and B. A. Bodo (1991). Trend analysis methodology for water quality time series. Environmetrics 2, 169-200.

[44] Khalili, D., T. Farnoud, H. Jamshidi, A. A. Kamgar-Haghighi, and S. Zand-Parsa (2011). Comparability Analyses of the SPI and RDI Meteorological Drought Indices in Different Climatic Zones. Water Resources Management 25, 1737-1757.

[45] Tao, W.-K., Y. N. Takayabu, S. Lang, S. Shige, W. Olson, A. Hou, G. Skofronick-Jackson, X. Jiang, C. Zhang, W. Lau, T. Krishnamurti, D. Waliser, M. Grecu, P. E. Ciesielski, R. H. Johnson, R. Houze, R. Kakar, K. Nakamura, S. Braun, S. Hagos, R. Oki, and A. Bhardwaj (2016). TRMM Latent Heating Retrieval: Applications and Comparisons with Field Campaigns and Large-Scale Analyses. Meteorological Monographs 56, 2.1-2.34.

[46] Hayes, M. J., M. D. Svoboda, D. A. Wilhite, and O. V. Vanyarkho (1999). Monitoring the 1996 Drought Using the Standardized Precipitation Index. Bulletin of the American Meteorological Society 80, 429-438.

[47] Filahi, S., M. Tanarhte, L. Mouhir, M. El Morhit, and Y. Tramblay (2016). Trends in indices of daily temperature and precipitations extremes in Morocco. Theoretical and Applied Climatology 124, 959-972. 